\title{
FACT FINDING AND ANALYSIS IN THE DEVELOPMENT OF TIMBER MANAGEMENT PLANS
}

by D. MCCOLL

\section{H. R. MacMillan Export Company Limited, Vancouver, British Columbia.}

From trial and error the forest industry has reached its own conception of good timber management which finds expression in economical harvesting and conversion to useful products. A different concept, however, is now becoming apparent through a better appreciation of the growth potentialities of our forests and through policies which aim to encourage sustained yield management. These two concepts are not irreconcilable, but need to be properly fused into a better and sounder business.

For over a decade there has been a strong trend toward better utilization. This trend gained impetus by virtue of an extraordinary demand created by the war, coupled with depletion of forest resources in certain areas. A marked increase in stumpage value has resulted. The need for close association between research and promotion agencies is quite apparent in order to successfully insure continued healthy rates of progress in better utilization, and in order to leave cut-over lands in a productive state. Capital invested in costly conversion plants must be protected by an assured supply of raw materials.

Timber management today requires more extensive data concerning both qualitative and quantitative timber appraisals; also more information about soil and topographical conditions, in order to develop an intelligent and dependable analysis which is required for so many purposes. Successful management control depends upon reliable facts concerning all details of the timber and ground, expressed in well-compiled maps and records.

Increased utilization, increased stumpage value and a diminishing supply of forest wealth are the chief factors which alert us to the necessity for gathering greater details concerning our timber inventories and, indeed, for more orderly removal of timber, aimed at reduction of wastage and disposal, to the best market advantage. Modern forest management's chief concern, therefore, is the harvesting of forest wealth and the sustaining of forest growth in a sound, economical manner. The engineer and forester are called upon to analyse the facts which they gather in the field and to submit plans for formulating policies covering logging development and sustained forest growth. The importance of having well-compiled and complete data should be better recognized by industry.

The forester's preliminary contribution to timber management embraces, primarily: Forest Utilization and Forest Protection.

The term Forest Utilization implies orderly harvesting practices and the greatest economical volume return by correlating cutting plans with market requirements.

1 Paper presented at a meeting of the Vancourer Section C.S.F.E., held at Vancouver, March 25th, 1949. 
Forest Protection involves the problems of fire, insect and disease control, and in keeping forest lands in a productive state. Having complete information and dependable topographical maps, the opportunity is afforded the forester for projecting plans which will provide for fire-breaks, seed patches and the early liquidation of over-mature, wind-blown and diseased timber. Stability in land use is evolving and this trend will continue. The forester will be brought into more prominent play inasmuch as there are many involved problems in respect to land classification, soil and site surveys. Much is yet to be done in these fields which will require more intensive surveys and more of the forester's time.

From the production and engineering standpoint, management puts together the assembled facts in the formulation of a policy respecting development, methods of logging and types of equipment. Here, too, dependable field data and carefully prepared topographical maps are found indispensable. Various methods for timber recovery may be projected with confidence, the primary transportation system determined-either truck or railroad-and the most suitable location for roads disclosed in relation to road costs and logging methods. Logging costs and realization values can be forecast within a reasonable degree of accuracy by the operator, who has available all the necessary facts pertaining to his timber and operations. Reliable field information, transposed to dependable topographical and timber-type maps, brings more people into the picture in planning forward development; the surest guide for removing most of the guess work from logging, and an invaluable means in planning the re-establishment of logged-over areas for future timber crops. The interdependence of engineer and forester is undeniable, and it marks an interesting forward step in the forest industry.

There are four major steps involved in gathering and assembling the necessary facts conducive to good forest management practice:

(I) Determination of area and location of timber. This may be by Air Survey, or conventional ground methods.

(II) Base Control and Strip Lines suitable for use' in cruising and topographic mapping.

(III) Quantitative and Qualitative cruising of timber species; also classification of sites and soils, and recording of non-commercial coverages.

(IV) Development of a large scale timber type and topographic map, for operational purposes, and secondary sheets showing matters relative to forestry.

A Planimetric Air Survey, in most instances, will be found a helpful supplement to ground examination. It is certainly an improved means for determining whether a field examination is warranted, since a reasonable estimate of total volume may be quickly had, and a general idea formed respecting development possibilities. Air photos are very useful, too, in planning ground surveys, since streams, lakes, bluffs and wind-throw, as hazards to base-lines, are brought into focus. Timber edges are quite clearly defined. Scrub areas can be delineated with a considerable degree of accuracy. These factors, 
combined, have a marked effect in reducing the cost of field examinations of the larger size areas especially. Planimetric mapping costs are relatively. inexpensive- 3 to 5 cents per acre and aerial photography costs are about the same.

Aerial Survey may be used to further advantage by compiling topographic and timber-type maps through the transportation of data by the Multiplexmachine method. The results are sufficiently accurate to permit projecting logging plans in a preliminary manner at least. Scrub and merchantable timbered areas are quite discernible on the photos for transferring to the timber-type map. This method requires less base-line control than is otherwise necessary with a survey solely conducted on the ground. Excepting the main base control lines, the secondary base and strip lines may be planned and run in the field more effectively and confined within the timbered areas. Points of commencement can be readily determined by spot identification on the photos, and also by aid of control base lines established on the ground. As the industry becomes better acquainted with this system for map development, its adaptability will be appreciated as a practical and economical means applicable to many areas. Costs of topographic mapping by Multiplex, (scale $400 \mathrm{ft}$. to $\mathrm{I}$ inch and $20^{\prime}$ contour intervals) amount to possibly 40 cents per acre;- expressed on a per $M$ basis the costs are relatively nominal. In most cases, some additional field work is essential.

The value of having dependable and well-established base and strip lines requires little, if any, mention here. The importance of their common use by cruiser, engineer and forester through closer efforts for co-ordination may well be stressed, however. The grid system of control, if established in a thorough manner in advance of the fact-finding surveys, will eliminate duplication of cardinal lines in the field and prove a more accurate means for correlating all data from field to map.

Specifications covering surveys of base and strip lines are largely dependant upon peculiarity of the area and time limitations. The transit party may comprise two men only in areas having but little undergrowth and an extra man may be added whenever it is found expedient. Substantial pickets are set at 5-chain intervals and a galvanized metal tag, 4" square, with identification markings imprinted, is inserted into a nearby tree as a measure for more lasting reference. The transit party will average one mile per day under ordinary circumstances. Elevations on the main base lines are generally carried by Wye level and on secondary base lines from vertical vernier readings of the transit.

The strip lines are run by 2-man parties and pickets set and referenced with metal tag at each tally point of 5 chains distance. Slope charts, having a scale of $\mathrm{I}$ inch to $20 \mathrm{ft}$., with slope rays corresponding to the hand-level readings are used for computing the horizontal and vertical components of the slope chainages. Spacing of strip lines $330 \mathrm{ft}$. apart provides for a 20 per cent cruise and a thorough grid system suitable for the engineer and forester. It is not uncommon for a strip-party to establish 3 or even 4 miles of line 
in a day, if ideal conditions are encountered; 1 mile daily, however, may be taken as a fair average.

Topographic mapping in the field is best accomplished by the topographer following some distance behind the strip parties. This divorces one job from the other entirely. Having complete elevation control well in advance, the topographer's task is facilitated, which permits the recording of all the necessary data in a comprehensive manner; a standard legend to cover recurring features will be found useful to the topographer. The engineer should supervise the topographer's work most carefully if unable to undertake the job himself, since so much importance is attached to it. In addition to mapping the contours, the main items to record are:

(I) Timber density classes and predominate timber species; also descriptive remarks concerning the timber generally.

(II) Soil conditions and rock outcrops; gravel deposits suitable for road purposes.

(III) Water supplies in relation to adequacy for fire protection and other requirements essential for operating.

(IV) Characteristics of topographical features and timber on steeper slopes especially in respect to possible landing sites, road construction, establishing recoverable timber edges and the availability of tail-holds for skylining purposes. It is found prudent to note landing sites and benches by symbols, or to exaggerate the contour interval in order to accentuate these important features.

The forester's field work involves, chiefly, classification of growing sites, examination of logged-over areas for restocking progress, and the gathering of all the information which is necessary for the development of a Working Plan.

Restocking and site classification examinations are generally conducted by use of the strip and stocked quadrat methods. Strip lines may be run either 5 or 10 chains apart, and stakes set at intervals of 2 chains to mark the stations which are commonly 4 quadrats in size, each one representing $1 / 1000$ of an acre. One seedling per quadrat, if well established, is shown as representing 25 per cent restocking of the station, and 50 per cent restocking is considered satisfactory. The forester notes the types of vegetation and soil and other growth factors necessary in classifying growing sites. Snags and odd living trees which might be found standing in the denuded areas are also noted and later shown on the map in symbol form.

A Working Plan survey is made for the purpose of recording the data necessary to provide a complete inventory on which to base a Management $\mathrm{Plan}$, and to indicate future yield possibilities of the area; also, what immediate or short-term yields can be obtained from thinnings and from mature stands which will leave the residual stands in the best growing condition and to insure regeneration. The basic requirements for determining yield are: type, site, age and stocking. A reasonably close prediction of present and future yields is possible on any chosen rotation from the field data. From 
the maps produced, logging can be planned year by year to the best advantage of forest economy. Regulation of the cut can also be planned to secure a proper distribution of age classes for continuous yield. This is the ultimate aim of any long range forest management plan.

Enhanced stumpage values, increasing potentialities for utilization of forest crops, and increasing interest directed towards continuous yield, increase the cruiser's responsibility. He is now called upon to estimate the quality of the timber species, as well as quantity, and to record basic information relative to silviculture. Grading of the timber is found to be of inestimable help in appraising values, and for planning operations to suit market and conversion plant requirements. Possible ultimate uses for all the forest crop should be given consideration.

Whenever grading is attempted, a third man is added to the party, which permits the cruiser to concentrate his efforts solely on timber estimating and noting the immature stands. Intensity of cruise is now generally 20 per cent and the estimates are compiled for each ten acre block. Working to the new specifications, 2 miles of cruise lines may be managed per day working under favourable conditions, which represents a coverage of 80 acres. , Formerly, a 10 per cent cruise was the popular practice and only 2 men were in a party: With less data to record, 240 acres were commonly covered in a day. Pre-war costs of a 10 per cent cruise were about 35c. per acre. Current costs, in comparison, are possibly 4 or 5 times greater, accountable by doubling the cruise intensity, services of an extra man, increased labour costs and gathering of more comprehensive data in the field. The cost per thousand, however, is a relatively small one. The value of this basic information to management is surely appreciated.

An operational map having topographical and timber-type features is the basic one used by management for formulating its logging and silvicultural plans. It is generally drawn to a scale of 1 inch to $400 \mathrm{ft}$., although in steep broken ground a larger scale of 1 inch to 200 feet is often found advantageous. Contour intervals of 20 feet to illustrate the topography has sufficed satisfactorily since the introduction of this type of mapping to the timber industry about 30 years ago. The operational map may well be termed the work sheet, and as such, all pertinent facts in relation to timber descriptions and physical characteristics of the terrain should be noted clearly.

Colour classification schemes are found very effective for accentuating stand densities and species and logged and burned areas on the operational map. Stand densities and predominate species may be more effectively illustrated if shown on separate maps which will also provide a means for segregating the mature and immature stands, and the old growth and merchantable types by distinctive colour schemes. The forester, too, puts the colour system to very good use on his various type maps as the primary means of differentiation for site and age classifications, intensity of re-stocking, seed patches and fire-breaks, etc. Colour schemes have proven a helpful means in guiding the projections for road development and logging plans. 
The success of the forester's plans for continuous yield, and those of the logger for sound operating, depends upon high fire protection standards as a fundamental. Management must lead the way and concern itself with this very important problem, and implement a program that can be translated into effective pre-suppression and suppression activities in the field. Improved fire protection and control measures are necessary. Much can be done with today's logging practices and in planning forward developments which will decrease the cost, and increase the efficiency of tomorrow's protection. We are aware of the value of delayed settings, small slash areas, and clean logging as basic measures for sound fire protection. These same measures are of prime importance too in meeting many silvicultural requirements, minimizing the problem of slash disposal, and in reducing the general over-all fire risk.

Closer utilization of the forest stand is now becoming economical, and evidence of the past few years indicates that waste reduction will materially assist in lessening the problem of fire protection, slash disposal and establishment of new forest growth. On looking at the over-all picture, truck logging is seen as providing the best means for meeting the issue of restocking and improved protection, wherever this method may be practical to use; it has great elasticity for salvage recovery and provides better means of access for fire control than the rail.

In summation, may I repeat, that Timber Management Plans are best developed through close co-operation between the forester, the engineer and the operator, with the invaluable aid of the forest products specialist. The requisite for a successful operation is to encourage more of the key personnel -the practical men and the technicians - to assume their full share of responsibilities for constant improvement, if our present high living standards are to be maintained. The technically trained man is being called upon for greater service-he has much to sell to the industry-the industry has need for his services. 